\title{
Haemodilution as a cause of anaemia in coalworkers
}

\author{
B. W. B. CHAN \\ M.R.C. Pneumoconiosis Research Unit, Llandough Hospital, Penarth, Glam.
}

\begin{abstract}
Chan, B. W. B. (1969). Brit. J. industr. Med., 26, 237-239. Haemodilution as a cause of anaemia in coalworkers. Blood volume measurements were made in eight cases of anaemia in coalworkers, including four men with Caplan's syndrome (rheumatoid pneumoconiosis), and in eight non-anaemic patients with chronic lung disease without significant arterial hypoxia. The total blood volume and the plasma volume were significantly increased in the anaemic group but the red cell volume was almost identical in the two groups. These results suggest that haemodilution is an important factor in the anaemia of these patients.
\end{abstract}

A normochromic or slightly hypochromic anaemia is common in coalworkers with pneumoconiosis who attend the M.R.C. Pneumoconiosis Research Unit for the purpose of long-term assessment or therapy. The anaemia is usually mild in degree and presents few serious clinical problems though it assumes greater importance in patients with hypoxia due to the lung disease, in which reduced arterial oxygen saturation is superimposed on the reduced oxygencarrying capacity caused by the anaemia.

In the course of a study on iron kinetics in patients with coalworker's pneumoconiosis, it was found that the plasma volume and total blood volume in some patients were unexpectedly high. The present study was therefore undertaken to determine whether a true anaemia exists, i.e., whether the reduction of the haemoglobin level in the peripheral blood reflects a true reduction in the total red cell volume, or whether haemodilution due to an expanded plasma volume might be an important factor in the production of the anaemia.

\section{Patients}

The patients were miners or ex-miners whose lung disease was in a chronic and stable state at the time the tests were performed. Patients with congestive cardiac failure, purulent sputum or acute exacerbation of bronchitis within the preceding month were excluded from the study.

Sixteen patients were studied, comprising:
Group A - 'Anaemic group' (eight patients)

These patients were selected on the basis of a venous haemoglobin concentration $(\mathrm{Hb})$ of less than $12.5 \mathrm{~g}$./ $100 \mathrm{ml}$. They were eight consecutive cases of anaemia seen at the outpatient clinic of this Unit, with the exception of those cases with a clear diagnosis of iron deficiency anaemia, for example due to gastro-intestinal tract bleeding.

Group B - 'Non-anaemic group' (eight patients)

These patients were selected as controls on the basis of a haemoglobin concentration of $14.0 \mathrm{~g} . / 100 \mathrm{ml}$. or above. They were of similar age and social habits to the anaemic patients.

In order to avoid the inadvertent inclusion of cases of polycythaemia secondary to hypoxic lung disease the arterial blood oxygen saturation was measured in each case and a subject was only admitted to the control group if the saturation was $92 \%$ or more. This criterion for exclusion was not applied to the anaemic group but their arterial blood oxygen saturation was also measured and in all but one case it was above $92 \%$. The exception was a case with a saturation of $90.3 \%$. The age, diagnosis, $x$-ray category of pneumoconiosis, and Rose-Waaler titre of the patients are presented in Table 1. A RoseWaaler titre of less than 1:32 was considered to be negative.

\section{Methods}

Haemoglobin was measured by the cyanmethaemoglobin method. Haematocrit was measured using a Hawksley microhaematocrit centrifuge. Mean corpuscular haemo- 
TABLE 1

Age and Diagnostic Data on Patients Studied

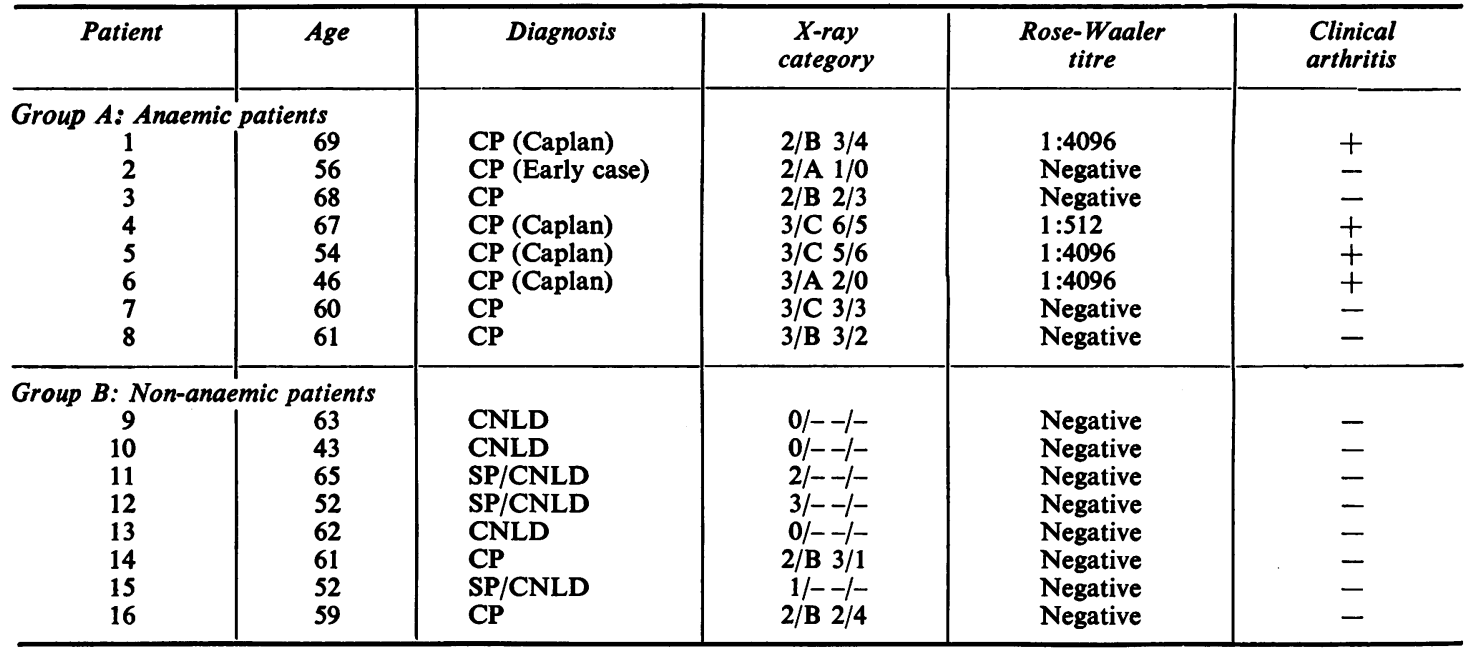

$\mathrm{CP}=$ complicated pneumoconiosis; $\mathbf{S P}=$ simple pneumoconiosis; $\mathrm{CNLD}=$ chronic non-specific lung disease; Caplan $=$ Caplan syndrome; $x$-ray category according to I.L.O. International Classification of Pneumoconiosis.

TABLE 2

Comparison of Peripheral Blood Data in Anaemic and Non-anaemic Patients

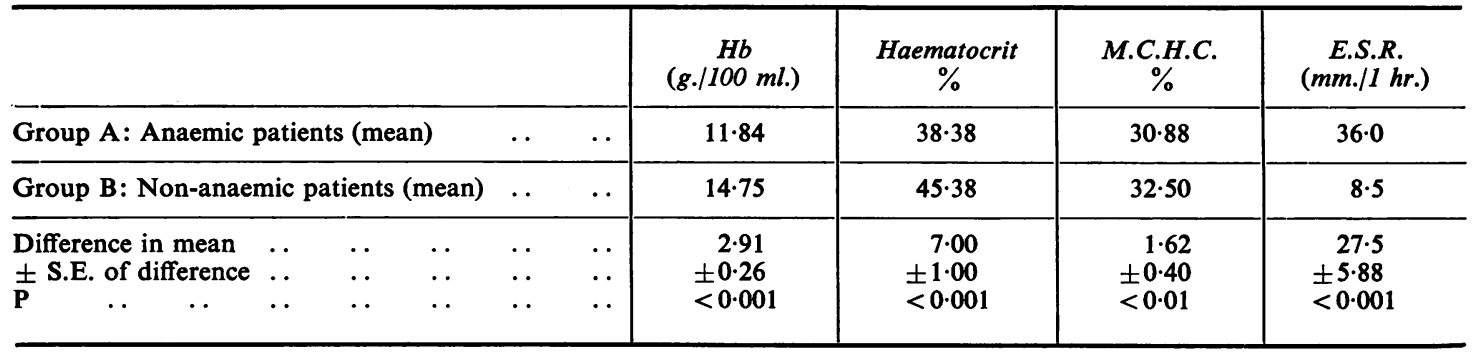

TABLE 3

\section{Comparison of Blood Volume Data in Anaemic and Non-anaemic Patients}

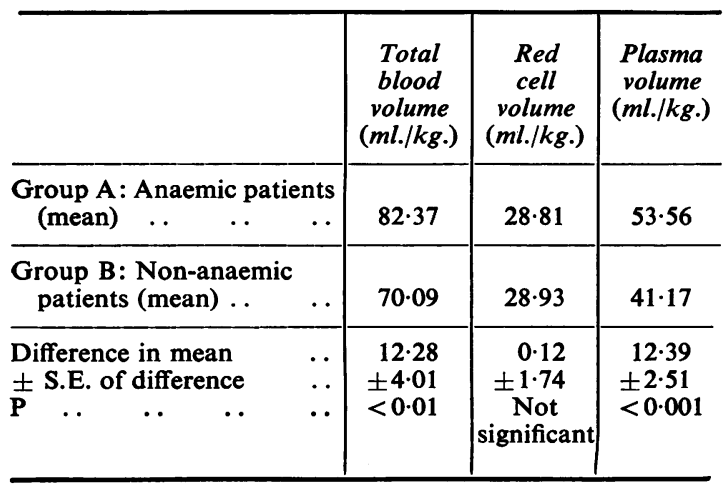

globin concentration (M.C.H.C.) was calculated from the haemoglobin and the haematocrit. The erythrocyte sedimentation rate (E.S.R.) was measured using the method of Westergren.

The red cell volume was measured using ${ }^{51} \mathrm{Cr}$-tagged red cells according to the method of Sterling and Gray (1950) as modified by Mollison and Veall (1955). Total blood volume was calculated from the red cell volume by assuming a whole body/venous haematocrit ratio of 0.91 (Chaplin, Mollison, and Vetter, 1953). Plasma volume was calculated as the difference between the total blood volume and the red cell volume.

Arterial blood was sampled from the brachial artery and analysed for oxygen saturation in a Unicam spectrophotometer by the method of Deibler, Holmes, Campbell, and Gans (1959).

\section{Results}

Peripheral blood findings are shown in Table 2 and results of measurements of the blood volume and its 
subdivisions are shown in Table 3. Differences in means between groups were analysed for significance using Students ' $t$ ' test for small numbers.

As would be expected from the selection procedure, the haemoglobin and haematocrit were significantly lower in the anaemic group. The M.C.H.C. was slightly but significantly reduced in this group and the E.S.R. was considerably increased.

The most striking finding, however, is that despite the lower haematocrit in the anaemic group, the red cell volume was almost identical in the two groups, while the anaemic group showed a significant increase in the plasma volume and the total blood volume. These results suggest therefore that while defective haemoglobinization of the cells (as shown by the M.C.H.C.) may be of minor importance, the main factor in the anaemia of these patients is haemodilution due to an increased plasma volume.

\section{Discussion}

The prevalence of anaemia in the Rhondda Valley, a typical Welsh mining valley, has been surveyed by Kilpatrick and Hardisty (1961). When the results were further analysed according to the $x$-ray category of pneumoconiosis, it was found that patients with complicated pneumoconiosis had a lower level of haemoglobin compared with patients with other forms of chronic lung disease or with subjects of similar age without lung disease (Kilpatrick, personal communication, 1967). In a previous study (unpublished) the haemoglobin levels of 66 patients, on whom arterial oxygen saturation studies had been performed, were analysed. It was found that patients with complicated pneumoconiosis had significantly lower haemoglobin levels compared with patients with chronic non-specific lung disease with or without simple pneumoconiosis. Since the arterial oxygen saturation was the same in both groups the observed difference in haemoglobin levels could not be due to a difference in the occurrence of hypoxic polycythaemia in some of the patients. Thus anaemia appears to be more common among patients with complicated pneumoconiosis. The present series, in whom all eight patients had complicated pneumoconiosis (though one patient was an early case), confirms this general trend.

The association between pneumoconiosis and rheumatoid arthritis was shown by Caplan (1953). Since anaemia is common in the latter condition it is perhaps appropriate to compare the present findings with results obtained in the anaemia of classical rheumatoid arthritis. Blood volume studies in this condition were reviewed by Read, Woodbury, Stapleton, and O'Neill (1962) who themselves contributed 88 cases. They found that the red cell volume was reduced and concluded that haemodilution was not an important factor in the production of the anaemia. In cases with splenomegaly, however, Weinstein (1964) found greatly increased red cell and plasma volumes. The results reported here appear to fall between these two situations. However, the series of Read and his colleagues (1962) probably included cases of simple iron deficiency anaemia, which is common among patients with rheumatoid arthritis in which gastro-intestinal blood loss may be a side effect of salicylate and steroid therapy. Their inclusion in a blood volume study may confuse the picture, and it is possible that moderate haemodilution in patients with rheumatoid arthritis without splenomegaly is commoner than is at present supposed.

In the present series four patients suffered from the rheumatoid pneumoconiosis syndrome. Their haematological data have been separately analysed and the degree of haemodilution was not found to be significantly different from that of the other four patients who did not have rheumatoid arthritis.

It is not clear at present why haemodilution should occur in these patients with coalworker's pneumoconiosis. None of the commoner causes of haemodilution anaemia, such as hepatic disease, nephrotic syndrome or splenomegaly, applies to these cases. Although subclinical fluid retention due to mild heart failure could not be entirely excluded, this seems unlikely to be an adequate explanation. Two of the patients were on small doses of steroids (less than $10 \mathrm{mg}$. of prednisone daily). It is significant that the E.S.R. is very much higher in the anaemic patients, and one may tentatively suggest that the haemodilution is part of a systemic disturbance occurring at a particularly active phase of the pneumoconiotic process.

\section{References}

Caplan, A. (1953). Certain unusual radiological appearances in the chest of coal-miners suffering from rheumatoid arthritis. Thorax, 8, 29-37.

Chaplin, H., Jr., Mollison, P. L., and Vetter, H. (1953). The body/ venous hematocrit ratio: its constancy over a wide hematocrit range. J. clin. Invest., 32, $1309-1316$.

Deibler, G. E., Holmes, M. S., Campbell, P. L., and Gans, J. (1959). Use of Triton X-100 as a hemolytic agent in the spectrophotometric measurement of blood $\mathrm{O}_{2}$ saturation. J. appl. Physiol., 14, 133-136.

Kilpatrick, G. S., and Hardisty, R. M. (1961). The prevalence of anaemia in the community. Brit. med. J., 1, 778-782.

Mollison, P. L., and Veall, N. (1955). The use of the isotope ${ }^{11} \mathrm{Cr}$ as a label for red cells. Brit. J. Haemat., 1, 62-74.

Read, H. C., Woodbury, J. F. L., Stapleton, J. E., and O'Neill, A. B. (1962). Anemia in rheumatoid arthritis. II. Blood volume studies. Canad. med. Ass. J., 87, 781-785.

Sterling, K., and Gray, S. J. (1950). Determination of the circulating red cell volume in man by radioactive chromium. J. clin. Invest., 29, 1614-1619.

Weinstein, V. F. (1964). Haemodilution anaemia associated with simple splenic hyperplasia. Lancet, 2, 21 8-223.

Received for publication October 4, 1968 